\title{
Mechanism of the Ventilatory Response to Carbon Monoxide
}

\author{
Teodoro V. Santiago and Norman H. Edelman \\ From the Pulmonary Diseases Division, Department of Medicine, College of \\ Medicine and Dentistry of New Jersey-Rutgers Medical School, \\ Piscataway, New Jersey 08854
}

\begin{abstract}
A B S TRACT The effects of carbon monoxide on ventilation were studied in unanesthetized goats. Responses to single breaths of $10-25 \% \mathrm{CO}$ in $\mathrm{O}_{2}$, which rapidly raised carboxyhemoglobin $(\mathrm{COHb})$ from 5 to $60 \%$, were considered to reflect peripheral chemoreceptor-mediated reflexes whereas responses to continuous inhalation of $1 \% \mathrm{CO}$ in $\mathrm{O}_{2}$, which slowly raised $\mathrm{COHb}$ from 0 to $60 \%$, were considered to reflect both peripheral chemoreceptor and nonperipheral chemoreceptor mechanisms. In each of six goats, single breaths of $\mathrm{CO}$ failed to elicit any immediate ventilatory response. However, slow buildup of carboxyhemoglobinemia in the same animals always elicited ventilatory stimulation (from a mean of 7.43 to $16.02 \mathrm{liter} / \mathrm{min}, \mathrm{P}<0.001$ ) beginning $5-6 \mathrm{~min}$ after onset of $1 \% \mathrm{CO}$ in $\mathrm{O}_{2}$ inhalation when $\mathrm{COHb}$ saturation reached $50-60 \%$. In eight studies of six animals $\mathrm{HCO}_{s}^{-}$concentration fell (from 21.3 to $15.8 \mathrm{meq} /$ liter $; \mathrm{P}<0.001$ ) and lactate concentration rose (from 2.5 to $4.2 \mathrm{meq} /$ liter; $\mathrm{P}<0.05$ ) in the cisternal cerebrospinal fluid during the $\mathrm{CO}$-induced hyperpnea. Additional studies ruled out ventilatory stimulation from left heart failure or enhanced chemosensitivity to carbon dioxide. Although the delayed hyperpnea was associated with a hyperdynamic cardiovascular response to $\mathrm{CO}$, blockade of these circulatory effects with propranolol (2 $\mathrm{mg} / \mathrm{kg}$ ) failed to abolish the delayed hyperpnea; however, the propranolol did unmask an element of ventilatory depression which preceded the hyperpnea. Conclusions were: (a) hyperventilation in response to $\mathrm{CO}$ inhalation is not mediated by the carotid bodies; $(b)$ the delayed hyperpnea in response to $\mathrm{CO}$ inhalation is primarily due to braincerebrospinal fluid acidosis; (c) mobilization of body $\mathrm{CO}_{2}$ stores due to the circulatory response to $\mathrm{CO}$ may obscure an initial depression of ventilation by $\mathrm{CO}$.
\end{abstract}

\section{INTRODUCTION}

The increase in ventilation caused by reduction in arterial $\mathrm{O}_{2}$ tension is well known and clearly ascribed

\footnotetext{
Received for publication 12 August 1975 and in revised form 6 November 1975.
}

to peripheral chemoreceptor stimulation. The ventilatory response is less clear when arterial oxygen content is decreased in the presence of normal oxygen tensions. One such state, carboxyhemoglobinemia, has attracted considerable attention in previous attempts to answer this question. No consistent pattern has emerged from these studies. John Haldane (1), for example, in a famous experiment performed on himself, hyperventilated after carbon monoxide inhalation. This was confirmed by Haggard and Henderson in dogs (2), and more recently by Ayres et al. in man (3), but Chiodi et al. (4) found no ventilatory changes in human subjects with carboxyhemoglobin $(\mathrm{COHb})^{1}$ levels as high as $50 \%$. Similarly, there is no agreement as to whether or not carboxyhemoglobinemia increases neuronal activity from the peripheral chemoreceptors (5-7).

In a recent study of a related problem, the ventilatory response to hypoxia in severe anemia (8), we pointed out the complexities inherent in experiments of this nature. Our data indicated that while diminished $\mathrm{O}_{2}$ content of arterial blood did not seem to be a ventilatory stimulus per se, it could substantially alter both peripheral chemoreceptor- and central nervous system-mediated responses to hypoxic hypoxia. Thus, the clinical significance of defining the ventilatory response to carbon monoxide goes beyond the occasional case of carbon monoxide poisoning since it is likely to shed light upon ventilatory adjustments to a variety of situations in which the central nervous system is deprived of its normal supply of oxygen.

In the current study, we attempted to understand the mechanisms that determine the ventilatory responses to carbon monoxide of intact unanesthetized animals. We used a methodologic approach which allowed for distinction between peripheral chemoreceptor- and central nervous system-mediated responses. This was made possible by taking advantage of the previously demonstrated differences in time of onset of these effects. Peripheral chemoreceptor-mediated responses, which

${ }^{1}$ Abbreviations used in this paper: $\mathrm{COHb}$, carboxyhemoglobin; CSF, cerebrospinal fluid. 
take less than $10 \mathrm{~s}$ to become manifest (9), were tested by inhalations of single breaths of $\mathrm{CO}$ in $\mathrm{O}_{2}$. The combined peripheral chemoreceptor- and central nervous system-mediated responses (the latter take at least a minute to develop) (10) were tested by continuous inhalation of $1 \% \mathrm{CO}$ in $40 \% \mathrm{O}_{2}$. To confirm the validity of this approach, and to elucidate the mechanisms involved in the ventilatory responses that were observed, additional studies were done. They involved denervation of the carotid bodies, monitoring of cerebrospinal fluid (CSF) acid-base changes, and evaluation of the effects of the concomitant circulatory changes during inhalation of carbon monoxide. The data support the view that acute carboxyhemoglobinemia does not stimulate peripheral chemoreceptors and provide a basis for a multifactorial concept of the ventilatory effects of central nervous system hypoxia.

\section{METHODS}

28 goats were studied unanesthetized and in the standing position. During the week before performance of the experiments, an indwelling arterial catheter was inserted into a femoral artery under general anesthesia. During the study, this catheter was connected by means of a three-way stopcock to a calibrated blood pressure transducer (model P23 Dd, Statham Instruments Div., Gould, Inc., Oxnard, Calif.). This system enabled continuous monitoring of heart rate and arterial blood pressure; it also provided easy access to arterial blood with no disturbance to the animal. The animals were studied standing and lightly restrained by the horns to a stock. They were allowed to breathe through a snugly fitting mask with an attached Rudolph one-way valve. A Fleisch pneumotachograph was interposed in the inspiratory line, and attached to a (Statham PM 15) differential pressure transducer. The pressure signal was converted into a signal proportional to tidal volume by means of an integrator circuit (Electronics for Medicine, Inc., White Plains, N. Y.). Volume calibrations were made with a 2-liter syringe two times during the course of each study.

Transient carbon monoxide breathing. These experiments in six animals involved brief inhalations of $\mathrm{CO}$ in $\mathrm{O}_{2} . \mathrm{Be}-$ fore each study, the goats were anticoagulated with heparin $(2 \mathrm{mg} / \mathrm{kg})$ in order to facilitate the rapid withdrawal of blood from the arterial catheter. During each study, ventilation, heart rate, and blood pressure were continuously recorded. After breathing $40 \% \mathrm{O}_{2}$ in $\mathrm{N}_{2}$ until steady ventilation was observed $(10-15 \mathrm{~min})$, the animals were given 1 breath of $10-25 \% \mathrm{CO}$ in $40 \% \mathrm{O}_{2}$ plus $\mathrm{N}_{2}$. They then continued to breathe $40 \% \mathrm{O}_{2}$ in $\mathrm{N}_{2}$. An arterial blood sample was obtained $5 \mathrm{~s}$ after each $\mathrm{CO}$ exposure. These studies were repeated with different concentrations of $\mathrm{CO}$ in $\mathrm{O}_{2}$ in order to obtain a range of values for $\mathrm{COHb}$ levels. Because of the slow clearance of $\mathrm{CO}$ from the blood, repeat studies were done at intervals of hours to days. Measurements of arterial $\mathrm{Po}_{2}, \mathrm{pH}$, and $\mathrm{Pco}_{2}$ were made electrometrically at $37^{\circ} \mathrm{C}$ (Radiometer, Cleveland, Ohio), and measurement of hemoglobin concentration, $\mathrm{O}_{2}$ saturation, and $\mathrm{CO}$ saturation were made spectrophotometrically (CO oximeter, Instrumentation Laboratory, Inc., Lexington, Mass.).

Since conventional tests of peripheral chemoreceptor function involve ventilatory responses to reductions in oxygen tension, a second set of experiments was done for com- parison. In these studies, involving the same six animals, decreases in arterial $\mathrm{O}_{2}$ saturation were produced by transient inhalations of nitrogen. During each period of nitrogen breathing (2-8 breaths), ventilation and oxygen saturation (0-500 cuvette oximeter, Waters Instruments, Inc., Rochester, Minn.) were continuously recorded. To quantitate the responses to transient $\mathrm{N}_{2}$ inhalation the maximal increase in ventilation was related to the maximal fall in $\mathrm{O}_{2}$ saturation for each period of inhalation of the test gas. The rationale and details of this method have been previously described (8).

The results were plotted together, comparing the ventilatory responses to decreases in arterial $\mathrm{O}_{2}$ saturation achieved with either nitrogen or carbon monoxide inhalation. Failure to increase ventilation within $30 \mathrm{~s}$ of inhalation of the test gas was considered to signify lack of response to transient hypoxia.

Extended carbon monoxide breathing. On separate days, the same six animals breathed $40 \% \mathrm{O}_{2}$ in $\mathrm{N}_{2}$ for $10 \mathrm{~min}$ followed by $1 \% \mathrm{CO}$ in $40 \% \mathrm{O}_{2}$ plus $\mathrm{N}_{2}$ for $7-13$ min. Ventilation, arterial blood pressure, and heart rate were monitored as before. Arterial blood was sampled every minute and measurements of $\mathrm{pH}$, gas tensions, arterial $\mathrm{So}_{2}$, and $\mathrm{COHb}$ were carried out as described above. While the total duration of the study varied from animal to animal the end point was consistent in each animal; this was the development of sustained hyperpnea (see Results). This end point was chosen after preliminary studies showed that if animals were allowed to breathe $\mathrm{CO}$ beyond the establishment of sustained hyperventilation, apnea ensued within 2-4 min. After the inhalation of $1 \% \mathrm{CO}$ they resumed breathing $40 \% \mathrm{O}_{2}$ in $\mathrm{N}_{2}$.

We then tried to determine the mechanisms responsible for the delayed hyperpnea which was observed during extended inhalation of $\mathrm{CO}$. The following possibilities were entertained: $(a)$ heightened medullary chemoreceptor sensitivity causing an enhanced response to $\mathrm{CO}_{2}$; this was considered as a possibility since another form of hypoxia (inhalation of gases with low oxygen tension) is known to enhance the ventilatory response to $\mathrm{CO}_{2}$ in both man and goats (11); (b) left heart failure causing pulmonary edema or congestion; $(c)$ delayed peripheral chemoreceptor stimulation; $(d)$ central nervous system acidosis; and $(e)$ concomitant circulatory changes. To check each possibility, the following additional studies were done.

Ventilatory responses to carbon dioxide. This was measured in five goats by a rebreathing technique. Studies were done before $\mathrm{CO}$ inhalation $(\mathrm{COHb}=0-3 \%)$ and at $\mathrm{COHb}$ levels of $20-30$ and $40-60 \%$. Buildup of $\mathrm{COHb}$ levels was accomplished by inhalation of $1 \% \mathrm{CO}$ in $40 \%$ $\mathrm{O}_{2}$ as described above. Then the one-way breathing valve was removed and the animals were allowed to rebreathe from a 13-liter bag half filled with $5 \% \mathrm{CO}_{2}$ and $95 \% \mathrm{O}_{2}$. The pneumotachograph was repositioned into the tubing that connected the breathing mask to the bag. At 20 -s intervals, arterial blood samples were drawn for measurement of the variables listed above. The closed rebreathing system had the advantage of ensuring the constancy of the desired $\mathrm{COHb}$ level throughout each study. The results were evaluated in the conventional way by relating changes in ventilation to changes in arterial $\mathrm{PCO}_{2}$.

Pulmonary artery catheterization. In two animals catheterization of the pulmonary artery was done to test for left heart failure. Before the study a balloon-tipped (SwanGanz) catheter was inserted percutaneously through the jugular vein under local anesthesia and floated under fluoroscopy to the pulmonary artery. This was attached to a 
blood pressure transducer (Statham P23 Dd). During inhalation of $1 \% \mathrm{CO}$ in $40 \% \mathrm{O}_{2}$, serial measurements were made of blood pressure in the pulmonary artery and pulmonary veins ("wedge pressure," by inflation of the balloon).

Carotid body denervation. To investigate the role played by the peripheral chemoreceptors in the delayed hyperventilation, we repeated the extended $\mathrm{CO}$ studies in four goats after bilateral carotid body denervation, which was performed as described by Tenney and Brooks (12). To assess the efficacy of the chemodenervation procedure, ventilatory responses to transient nitrogen inhalation of these animals were tested before and after surgery, by the method described above. Only animals that showed complete abolition of ventilatory responses to transient hypoxia were included in this study.

CSF acid-base changes. Eight additional studies were done in six animals to determine CSF acid-base status. For these experiments, a Seldinger needle (BD-18-T) was percutaneously inserted under local anesthesia into the cisterna magna. Needle placement was initially verified by fluoroscopy until sufficient confidence with the technique had been developed. Base-line ventilation, arterial blood, and CSF samples were obtained with the animals breathing $40 \% \quad \mathrm{O}_{2}$ in $\mathrm{N}_{2}$. With the cisternal needle still in place, the animals were switched to $1 \% \mathrm{CO}$ in $40 \% \mathrm{O}_{2}$. The measurements were repeated at the height of hyperventilation, and 2-3 min after termination of CO inhalation while the animals again breathed $40 \%$ oxygen in nitrogen. Samples of blood and $\mathrm{CSF}$ were analyzed for $\mathrm{pH}$ and $\mathrm{PCO}_{2}$ as well as for lactate levels by an enzymatic method (13). CSF bicarbonate levels were calculated from $\mathrm{pH}$ and $\mathrm{PCO}_{2}$ by using a $\mathrm{pK}_{1}$ of 6.13 .

Circulatory changes. Wasserman and co-workers (14) have demonstrated that an abrupt increase in cardiac output may cause isocapnic hyperpnea. Since our data indicated that arterial $\mathrm{PcO}_{2}$ did not decrease in proportion to the degree of hyperpnea observed during inhalation of $\mathrm{CO}$ and suggested that significant increases in cardiac output occurred during this time, we tested whether this phenomenon could have contributed to the observed pattern of responses to inhalation of $\mathrm{CO}$. In order to evaluate the role of the circulatory changes in the ventilatory phenomena observed, the studies of extended inhalation of carbon monoxide were repeated after beta-adrenergic blockade produced by intravenous infusion of propranolol at a dose of $2 \mathrm{mg} / \mathrm{kg}$ in four goats.

Finally, studies were done in four animals to determine whether there was mobilization of $\mathrm{CO}_{2}$ from body stores during inhalation of $\mathrm{CO}$ as would be required if the phenomenon described by Wasserman and co-workers was operative during inhalation of carbon monoxide. $\mathrm{O}_{2}$ uptake and $\mathrm{CO}_{2}$ elimination were measured while the animals breathed $40 \% \mathrm{O}_{2}$ in $\mathrm{N}_{2}$. After this, the animals breathed $1 \% \mathrm{CO}$ in $40 \% \mathrm{O}_{2}$ plus $\mathrm{N}_{2}$ until hyperpnea was established for approximately $1 \mathrm{~min}$. They then were returned to the $40 \% \mathrm{O}_{2}$ and $\mathrm{N}_{2}$ gas mixture, whereupon $\mathrm{O}_{2}$ uptake and $\mathrm{CO}_{2}$ elimination were again measured over the next minute while the hyperpnea persisted. Standard methods were used for these determinations. Heart rate and blood pressure were recorded in these studies as well.

\section{RESULTS}

Transient carbon monoxide breathing. Fig. 1 relates changes in ventilation to decreases in arterial oxygen saturation during transient inhalation of nitrogen or of

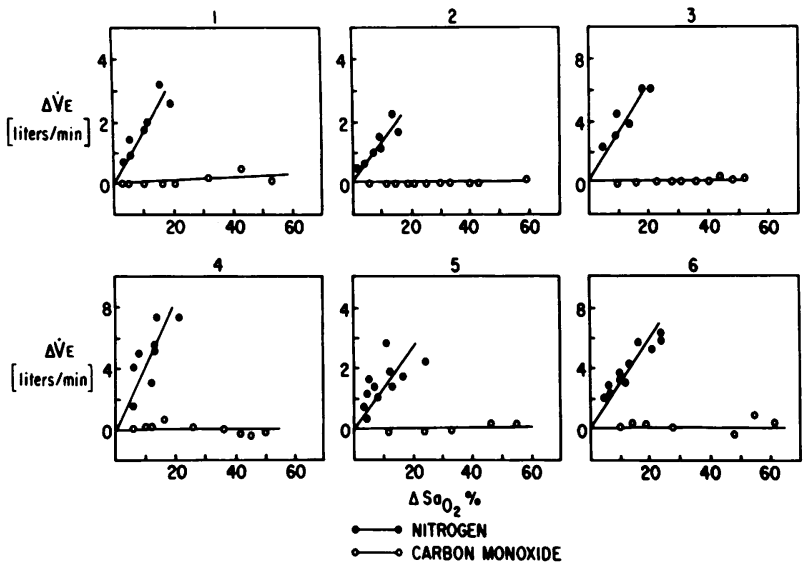

Figure 1 The ventilatory response to transient hypoxia of six goats. Change in ventilation $(\Delta \mathrm{VE})$ is plotted against falls in arterial $\mathrm{O}_{2}$ saturation $\left(\Delta \mathrm{SaO}_{2} \%\right)$ produced by either $2-8$ breaths of $100 \%$ nitrogen (shaded circles) or 1 breath of 10-25\% carbon monoxide (open circles). Ventilatory stimulation consistently followed nitrogen inhalation. In contrast, rapid buildup of carboxyhemoglobinemia produced no ventilatory changes.

carbon monoxide in $\mathrm{O}_{2}$ for each of six goats. A consistent stimulation of ventilation which was related in a linear fashion to decrease in arterial $\mathrm{So}_{2}$ always followed nitrogen inhalation. Carbon monoxide produced no ventilatory changes despite falls in arterial $\mathrm{So}_{2}$ of as much as $60 \%$. Values for arterial $\mathrm{O}_{2}$ tension were always above $150 \mathrm{~mm} \mathrm{Hg}$ during transient $\mathrm{CO}$ inhalation. These data suggested that abrupt decreases in $\mathrm{O}_{2}$ content of arterial blood while $\mathrm{O}_{2}$ tension was kept high did not stimulate the peripheral chemoreceptors sufficiently to elicit a ventilatory response.

Extended carbon monoxide breathing. The timecourse of ventilatory responses to inhalation of $1 \% \mathrm{CO}$ in $40 \% \mathrm{O}_{2}$ is illustrated in Fig. 2. No ventilatory changes occurred between 1 and $5 \mathrm{~min}$ ( $\mathrm{COHb}$ range $=0-50)$. Beyond $5 \mathrm{~min}$, a progressive increase in ventilation occurred (average increase $=8.59$ liters/ $\mathrm{min})$. This ventilatory stimulation was seen in all six animals and had its time of onset between 5 and 10 min, which corresponded to $\mathrm{COHb}$ levels of $40-50 \%$. Not shown on this figure is the observation that apnea occurred if $\mathrm{COHb}$ levels were allowed to rise beyond levels of 70-75 percent. Apnea was frequently associated with an inability to stand in the stock but loss of consciousness or seizures were not observed. Apneic animals could always be resuscitated without apparent residual effects by tracheal intubation and mechanical ventilation with $100 \% \mathrm{O}_{2}$.

In all animals, arterial $\mathrm{PCO}_{2}$ tended to rise within 2-3 $\mathrm{min}$ and then return to near control levels during the hyperventilation phase (Fig. 2). Tachycardia was manifest at 2-3 min and progressed throughout inhala- 
TABLE I

Ventilatory, Acid-Base, and Hemodynamic Data during Extended Carbon Monoxide Breathing

\begin{tabular}{|c|c|c|c|c|c|c|c|c|c|}
\hline Goat & VE & VT & $\mathrm{f}$ & $\mathrm{COHb}$ & $\mathrm{PaO}_{2}$ & $\mathrm{pH}$ & $\mathrm{Pa}_{\mathrm{CO}_{2}}$ & HR & BP \\
\hline & liters/min & $\mathrm{cm}^{2}$ & $\min ^{-1}$ & $\%$ & $m m \mathrm{Hg}$ & & $m m \mathrm{Hg}$ & $\min ^{-1}$ & $m m \mathrm{Hg}$ \\
\hline \multirow[t]{2}{*}{1} & 7.43 & 413 & 18 & 0.2 & 142 & 7.35 & 38 & 80 & $132 / 98$ \\
\hline & 17.78 & 450 & 40 & 60.0 & 145 & 7.33 & 40 & 120 & $200 / 128$ \\
\hline \multirow[t]{2}{*}{2} & 8.53 & 276 & 32 & 0.8 & 163 & 7.38 & 32 & 75 & $110 / 72$ \\
\hline & 15.39 & 453 & 34 & 52.9 & 159 & 7.36 & 35 & 156 & $135 / 88$ \\
\hline \multirow[t]{2}{*}{3} & 6.60 & 236 & 28 & 3.6 & 162 & 7.38 & 36 & 75 & $112 / 75$ \\
\hline & 17.50 & 416 & 42 & 68.0 & 199 & 7.39 & 34.5 & 181 & $148 / 106$ \\
\hline \multirow[t]{2}{*}{4} & 7.47 & 162 & 46 & 1.3 & 158 & 7.47 & 29.8 & 88 & $150 / 92$ \\
\hline & 15.56 & 260 & 60 & 55.4 & 175 & 7.44 & 33.5 & 156 & $178 / 108$ \\
\hline \multirow[t]{2}{*}{5} & 9.14 & 301 & 30 & 2.6 & 122 & 7.46 & 29.5 & 98 & $135 / 90$ \\
\hline & 16.82 & 352 & 48 & 61.4 & 179 & 7.46 & 31.0 & 159 & $162 / 100$ \\
\hline \multirow[t]{2}{*}{6} & 5.41 & 450 & 12 & 3.3 & 135 & 7.43 & 39.5 & 137 & $105 / 85$ \\
\hline & 13.09 & 312 & 42 & 67.5 & 149 & 7.40 & 38.5 & 232 & $127 / 100$ \\
\hline
\end{tabular}

VE, minute ventilation; VT, tidal volume; $\mathrm{f}$, respiratory rate; $\mathrm{COHb}, \mathrm{COHb}$ saturation of arterial blood; $\mathrm{Pa}_{2}$, oxygen tension in arterial blood; $\mathrm{Pa}_{\mathrm{CO}_{2}}$, carbon dioxide tension in arterial blood; $\mathrm{HR}$, heart rate; $\mathrm{BP}$, systolic/diastolic blood pressure.

tion of $\mathrm{CO}$. When hyperpnea was established heart rates had increased by $85 \%$ of control, pulse pressures had increased by $40 \%$ and mean blood pressures increased an average of $16 \%$ of control values. Ventilatory and circulatory measurements made in the control state and $1 \mathrm{~min}$ after the onset of hyperventilation are listed in Table I.
Ventilatory response to COs. Fig. 3 depicts the ventilatory responses to $\mathrm{CO}_{2}$ in five animals at base line $(\mathrm{COHb}=0-3 \%)$, and at elevated $\mathrm{COHb}$ levels of $20-30 \%$ and $40-60 \%$. In three of the five animals, there was no change in slope of the $\mathrm{VE}-\mathrm{PCO}_{2}$ line. In two of the five animals, blunting of the ventilatory response to $\mathrm{CO}_{2}$ occurred at the highest $\mathrm{COHb}$ levels.

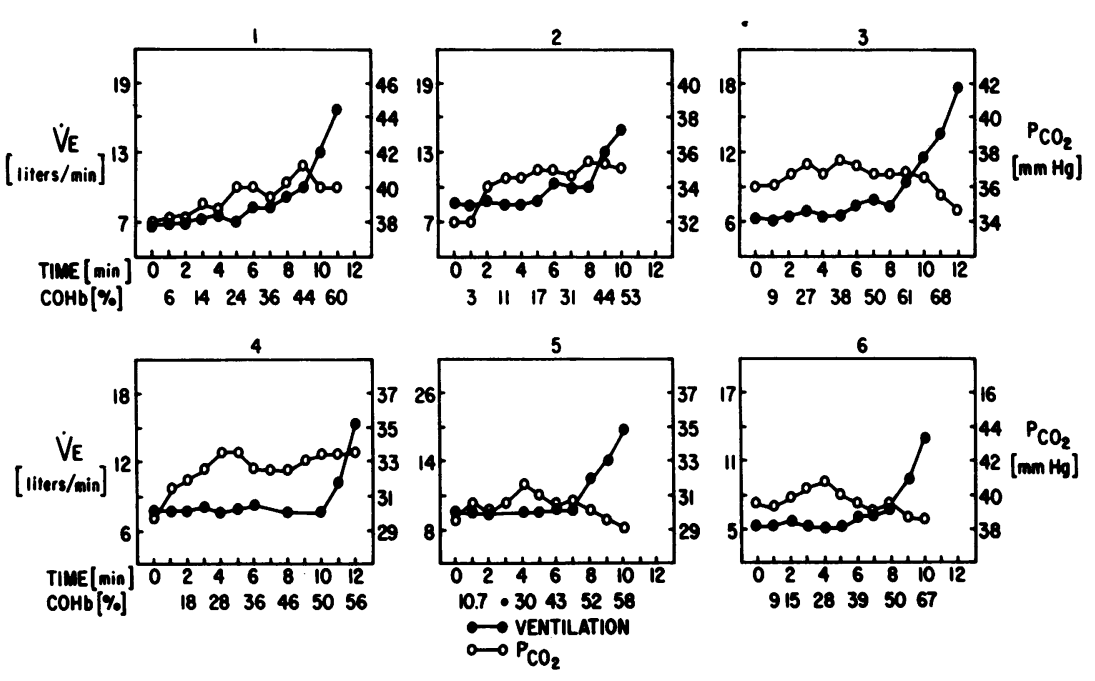

FIGURE 2 The ventilatory and concomitant arterial $\mathrm{PCO}_{2}$ changes provoked by $1 \%$ carbon monoxide inhalation are illustrated for six animals. Ventilation $(\mathrm{VE})$ is plotted against both time in minutes and $\mathrm{COHb}$ level. Slow buildup of carboxyhemoglobinemia produced no ventilatory changes between 1 and $5 \mathrm{~min}(\mathrm{COHb}=0-50 \%)$. Continuation of $\mathrm{CO}$ inhalation beyond this point always resulted in significant ventilatory stimulation. Arterial $\mathrm{PCO}_{2}$ rose during the first 1-5 min of $1 \%$ CO inhalation despite the absence of ventilatory changes and did not fall in proportion to the magnitude of the hyperpnea. 
Pulmonary artery catheterization. Studies in two goats indicated that there were no significant changes in mean pulmonary artery or pulmonary wedge pressures during inhalation of $1 \% \mathrm{CO}$ for sufficient time to cause hyperventilation.

Carotid body denervation. Four goats were studied before and after denervation of the carotid bodies. Fig. 4 shows that ventilatory responses to inhalation of $1 \%$ $\mathrm{CO}$ were unaltered after bilateral carotid body denervation.

Blood and CSF acid-base changes. Table II shows acid-base parameters and lactate concentrations in arterial blood and CSF samples taken before carbon monoxide inhalation and at the height of hyperpnea. Consistent decreases in $\mathrm{pH}$ (mean from 7.35 to 7.27 , $P<0.05$ ) and $\mathrm{HCO}_{3}{ }^{-}$(mean from 21.3 to $15.8 \mathrm{meq}$ / liter, $P<0.001$ ) of the CSF accompanied the delayed hyperpnea evoked by $\mathrm{CO}$ breathing. In contrast, there were no systematic changes in blood $\mathrm{pH}$ (mean remained at 7.45) or $\mathrm{HCO}_{3}^{-}$level (mean from 21.9 to $22.1 \mathrm{meq} /$ liter). CSF lactate level rose during $\mathrm{CO}$ inhalation in all animals (mean from 2.5 to $4.2 \mathrm{meq} / \mathrm{liter}$, $P<0.05)$. Blood lactate averaged $1.8 \mathrm{meq} / \mathrm{liter}$ and did not change systematically during $\mathrm{CO}$ inhalation.

Circulatory changes-effects of beta-adrenergic blockade. Table III lists the responses to extended $\mathrm{CO}$ inhalation in four animals before and after beta-adrenergic blockade with propranolol at a dose of $2 \mathrm{mg} / \mathrm{kg}$. Before propranolol, the heart rate averaged 102 in the control state and increased to $210 / \mathrm{min}$ at $\mathrm{COHb}$ levels of $50-70 \%$. After propranolol, this increase was significantly reduced; the heart rate averaged $80 / \mathrm{min}$ in the control state and increased to only $108 / \mathrm{min}$ at the
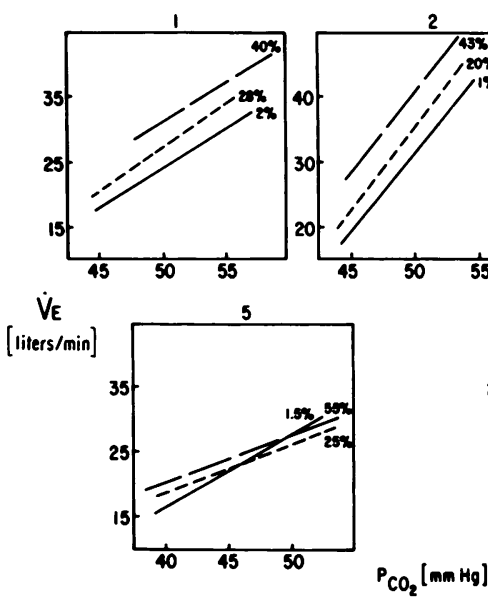

FIGURE 3 The effect of carboxyhemoglobinemia on the ventilatory responses to carbon dioxide of five goats. Ventilation $(\mathrm{VE})$ is plotted against arterial $\mathrm{PCO}_{2}$ tension. $\mathrm{COHb}$ levels $(\%)$ are affixed to each $\mathrm{VE}-\mathrm{PCO}_{2}$ line. Sensitivity to $\mathrm{CO}_{2}\left(\Delta \mathrm{VE} / \Delta \mathrm{PCO}_{2}\right)$ remained unchanged in three goats and was depressed by carboxyhemoglobinemia in two goats.
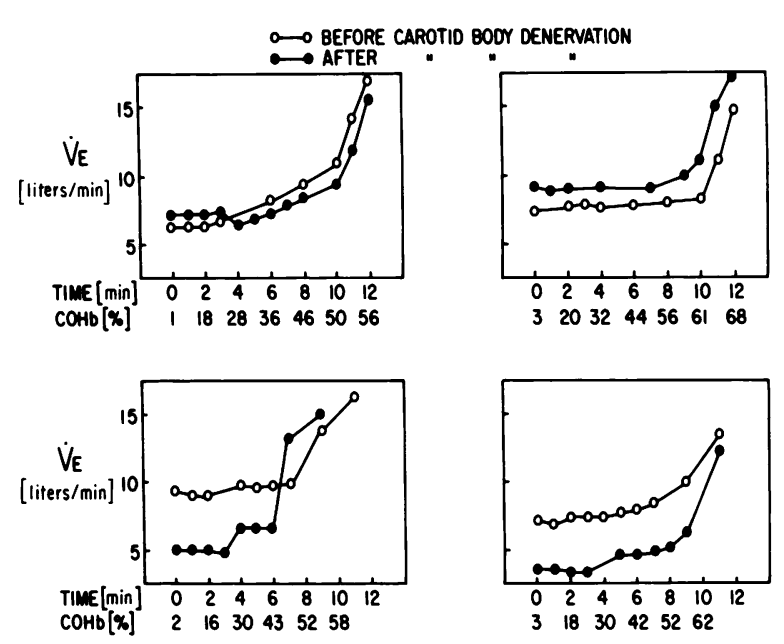

FIGURE 4 Ventilatory responses to $1 \%$ carbon monoxide inhalation before and after bilateral carotid body denervation in four goats are illustrated. The pattern and magnitude of the delayed ventilatory stimulation provoked by $1 \% \mathrm{CO}$ inhalation remained unchanged despite abolition of peripheral chemoreceptor function.

height of hyperventilation. There were two other effects of beta-adrenergic blockade. The magnitude of the delayed hyperpnea was reduced, but arterial $\mathrm{PCO}_{2}$ values during hyperpnea fell from base-line values. This is in contrast to the untreated animals in which $\mathrm{PCO}_{2}$ stayed the same or even increased despite a greater ventilatory response. In addition, Fig. 5 shows that in all four animals treated with propranolol, inhalation of $1 \% \mathrm{CO}$ produced varying degrees of ventilatory depression during the first five min of carbon monoxide inhalation $(\mathrm{COHb}=9-27 \%)$, a pattern that was not seen in any of the animals studied without propranolol.

Mobilization of tissue COs stores. Table IV lists ventilatory variables as well as $\mathrm{O}_{2}$ uptake, $\mathrm{CO}_{2}$ elimination, and calculated physiologic dead space in the control period and after $\mathrm{CO}$-induced hyperpnea had been established for $1 \mathrm{~min}$. As in the initial group of animals there were substantial increases in minute ventilation with either small or no changes in arterial $\mathrm{PCO}_{2}$ when $\mathrm{COHb}$ reached $50-60 \%$. The data in Table III indicated that this phenomenon could not be ascribed to an increase in the ratio of physiologic dead space ventilation to total minute ventilation; nor did it seem to reflect an increase in metabolic rate since $\mathrm{O}_{2}$ uptake remained constant. Thus, the increased $\mathrm{CO}_{2}$ elimination appeared to represent mobilization of $\mathrm{CO}_{2}$ from tissue stores.

\section{DISCUSSION}

This study has two basic findings : a lack of ventilatory response to inhalation of single breaths of carbon monoxide in $\mathrm{O}_{2}$ and a delayed increase of ventilation upon inhalation of $1 \% \mathrm{CO}$ in $40 \% \mathrm{O}_{2}$. 
TABLE II

Effect of Extended Inhalation of Carbon Monoxide on Acid-Base Status and Lactate Concentrations of Blood and Cisternal Cerebrospinal Fluid

\begin{tabular}{|c|c|c|c|c|c|c|c|c|c|}
\hline \multirow[t]{2}{*}{ Goat } & \multicolumn{5}{|c|}{ Arterial blood } & \multicolumn{4}{|c|}{ Cisternal fluid } \\
\hline & $\mathrm{COHb}$ & $\mathrm{pH}$ & $\mathrm{PcO}_{2}$ & $\mathrm{HCO}_{3}-$ & Lactate & $\mathrm{pH}$ & $\mathrm{PcO}_{2}$ & $\mathrm{HCO}_{3}^{-}$ & Lactate \\
\hline & $\%$ & & $m m \mathrm{Hg}$ & \multicolumn{2}{|c|}{ meq/liter } & & $m m \mathrm{Hg}$ & \multicolumn{2}{|c|}{ meq/liter } \\
\hline \multirow[t]{2}{*}{20} & 0.9 & 7.45 & 26.0 & 17.5 & 2.7 & 7.35 & 38.5 & 19.3 & 2.8 \\
\hline & 57.3 & 7.44 & 26.5 & 17.5 & 1.2 & 7.30 & 34.0 & 15.2 & 3.3 \\
\hline \multirow[t]{2}{*}{20} & 1.2 & 7.44 & 27.2 & 18.1 & 1.6 & 7.34 & 44.0 & 21.6 & 3.4 \\
\hline & 59.8 & 7.47 & 28.0 & 19.8 & 2.2 & 7.31 & 36.0 & 16.2 & 4.7 \\
\hline \multirow[t]{2}{*}{21} & 0.0 & 7.39 & 38.5 & 22.5 & 0.5 & 7.30 & 46.5 & 20.6 & 0.9 \\
\hline & 59.4 & 7.37 & 40.5 & 22.7 & 1.9 & 7.23 & 41.0 & 15.5 & 5.2 \\
\hline \multirow[t]{2}{*}{21} & 2.2 & 7.35 & 38.5 & 20.6 & 1.9 & 7.30 & 45.5 & 20.2 & 2.9 \\
\hline & 67.5 & 7.38 & 38.0 & 21.8 & 2.1 & 7.25 & 40.5 & 16.0 & 4.4 \\
\hline \multirow[t]{2}{*}{22} & 1.1 & 7.50 & 34.6 & 26.0 & 1.9 & 7.44 & 44.0 & 26.8 & 3.2 \\
\hline & 55.0 & 7.51 & 34.0 & 26.0 & 2.7 & 7.25 & 37.9 & 14.9 & 4.0 \\
\hline \multirow[t]{2}{*}{23} & 0.0 & 7.47 & 33.5 & 23.5 & 2.3 & 7.36 & 43.5 & 22.2 & 2.4 \\
\hline & 60.4 & 7.42 & 35.5 & 22.5 & 2.4 & 7.36 & 40.0 & 20.5 & 2.9 \\
\hline \multirow[t]{2}{*}{24} & 1.9 & 7.47 & 34.5 & 24.1 & 2.1 & 7.32 & 41.5 & 19.2 & 2.6 \\
\hline & 62.9 & 7.48 & 33.5 & 24.2 & 2.5 & 7.25 & 36.0 & 14.2 & 3.3 \\
\hline \multirow[t]{2}{*}{25} & 2.2 & 7.50 & 30.5 & 23.1 & 1.3 & 7.37 & 39.0 & 20.2 & 1.5 \\
\hline & 56.0 & 7.49 & 30.1 & 22.2 & 1.1 & 7.27 & 33.9 & 14.2 & 5.8 \\
\hline
\end{tabular}

Inhalation of single breaths of carbon monoxide. We interpret the lack of response to transient carbon monoxide exposures as indicating an absence of peripheral chemoreceptor response to falls in oxygen content at constant $\mathrm{O}_{2}$ tension of arterial blood. The consistent ventilatory stimulation that followed decreases
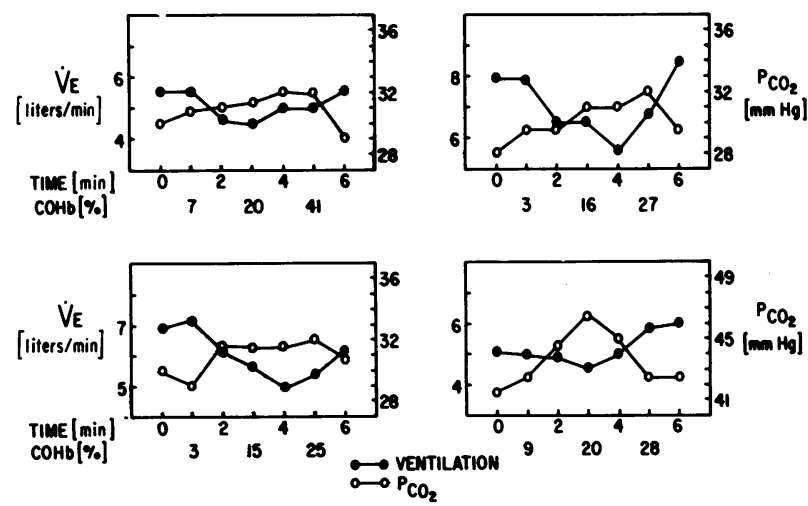

Figure 5 The effects of pretreatment with propranolol $(2 \mathrm{mg} / \mathrm{kg})$ upon ventilation and arterial $\mathrm{PCO}_{2}$ tension during the initial $6 \mathrm{~min}$ of $1 \% \mathrm{CO}$ inhalation are shown in four goats. Significant reduction of the circulatory response to carboxyhemoglobinemia by propranolol (see text) resulted in ventilatory depression during the first $6 \mathrm{~min}$ of $1 \% \mathrm{CO}$ inhalation. in $\mathrm{O}_{2}$ content produced by inhalation of nitrogen confirms previous observations that the main stimulus to the peripheral chemoreceptors is a fall in arterial $\mathrm{O}_{2}$ tension (15).

Similar findings have been recorded by Lloyd and co-workers (16), who reported no ventilatory stimulation after administration of single breaths of carbon monoxide to human volunteers. We and others $(8,17$, 18) have reported that no ventilatory stimulation followed significant reductions in oxygen content of arterial blood due to anemia. Although we found that enhancement of peripheral chemoreceptor responsiveness to lowering of $\mathrm{O}_{2}$ tensions was induced by anemia, this was abolished by alpha-adrenergic blockade, indicating that this effect was secondary to a heightened sympathetic tone rather than a direct response by the peripheral chemoreceptors to the diminished oxygen delivery.

These findings are in agreement with previous studies by Duke et al. (5), which indicated that carboxyhemoglobinemia did not cause an increase in chemoreceptor nerve fiber discharges. Two more recent studies, by Paintal (6) and by Mills and Edwards (7), reported increases in chemoreceptor nerve fiber discharge after inhalation of carbon monoxide. In both of these studies, however, the authors reported a time of onset of per- 
TABLE III

Effects of Beta-Adrenergic Blockade on Ventilatory and Circulatory Responses to Extended CO Inhalation

\begin{tabular}{|c|c|c|c|c|c|c|c|c|c|c|c|c|c|}
\hline \multirow[t]{2}{*}{ Goat } & \multirow[t]{2}{*}{$\mathrm{COHb}$} & \multicolumn{2}{|c|}{ VE } & \multicolumn{2}{|c|}{ Vt } & \multicolumn{2}{|c|}{$\mathrm{f}$} & \multicolumn{2}{|c|}{ HR } & \multicolumn{2}{|c|}{$\mathbf{B P}$} & \multicolumn{2}{|c|}{$\mathrm{Pa}_{\mathrm{CO}}$} \\
\hline & & Pre & Post & Pre & Post & Pre & Post & Pre & Post & Pre & Post & Pre & Post \\
\hline & $\%$ & \multicolumn{2}{|c|}{ liters/min } & \multicolumn{2}{|c|}{$\mathrm{cm}^{3}$} & \multicolumn{2}{|c|}{$\min ^{-1}$} & \multicolumn{2}{|c|}{$\min ^{-1}$} & \multicolumn{2}{|c|}{$m m \mathrm{Hg}$} & \multicolumn{2}{|c|}{$m m \mathrm{Hg}$} \\
\hline \multirow[t]{2}{*}{9} & 0 & 5.42 & 5.69 & 285 & 267 & 19 & 21 & 84 & 74 & $148 / 105$ & $145 / 110$ & 33 & 30 \\
\hline & 60 & 18.83 & 11.32 & 325 & 315 & 58 & 36 & 176 & 103 & $140 / 60$ & $133 / 80$ & 32 & 26 \\
\hline \multirow[t]{2}{*}{10} & 0 & 8.98 & 7.82 & 528 & 279 & 17 & 28 & 100 & 72 & $116 / 85$ & $110 / 83$ & 30 & 29.5 \\
\hline & 51 & 18.56 & 13.58 & 619 & 257 & 30 & 53 & 251 & 98 & $130 / 82$ & $100 / 40$ & 33 & 26 \\
\hline \multirow[t]{2}{*}{11} & 0 & 7.50 & 6.83 & 375 & 352 & 20 & 19 & 117 & 102 & $118 / 70$ & $118 / 79$ & 32 & 31.5 \\
\hline & 52 & 16.86 & 14.62 & 456 & 430 & 37 & 34 & 230 & 117 & $124 / 60$ & $136 / 83$ & 34 & 29 \\
\hline \multirow[t]{2}{*}{12} & 0 & 4.45 & 5.12 & 262 & 276 & 17 & 20 & 108 & 72 & $106 / 80$ & $115 / 72$ & 40.5 & 39.5 \\
\hline & 69 & 10.95 & 9.25 & 288 & 201 & 38 & 46 & 183 & 114 & $116 / 70$ & $128 / 72$ & 42.5 & 36.5 \\
\hline
\end{tabular}

See Table I for definitions of abbreviations.

ipheral chemoreceptor responses of several minutes. This differs markedly from the 2- to 3-s lag in response which follows inhalation of gases with low oxygen tension. While low diffusibility of $\mathrm{CO}$ in chemoreceptor tissue could account for this delay, our studies suggest that a more likely possibility is that the chemoreceptor stimulation that they found was a secondary phenomenon, possibly related to a transient increase in arterial $\mathrm{PcO}_{2}$ due to the circulatory response to $\mathrm{CO}$ (see below) or to a less specific generalized excitatory state.

Delayed hyperpnea due to inhalation of $1 \%$ carbon monoxide. Extended carbon monoxide breathing, on the other hand, caused delayed hyperpnea. The phenomenon was highly reproducible and always reversible. It seemed to depend on both $\mathrm{COHb}$ level and time of exposure. The importance of the latter is underscored by the absence of ventilatory stimulation when equival- ent decreases in arterial $\mathrm{O}_{2}$ content were produced by rapid buildup of carboxyhemoglobinemia during the "single-breath" studies. The minimum $\mathrm{COHb}$ level needed to achieve this effect was not determined in these experiments since we did not hold that variable independent of time.

Several possible mechanisms for the delayed ventilatory stimulation provoked by $\mathrm{CO}$ breathing were considered. The possibility of delayed peripheral chemoreceptor stimulation was made unlikely by the reproducibility of the phenomenon after bilateral carotid body denervation. A contribution by the aortic bodies cannot be ruled out since they remained intact. Although the studies of Tenney and Brooks (12) suggest that the relative contribution of the aortic bodies to ventilatory control may be significant in goats, one would have to postulate a mode of action which was

TABLE IV

Gas Exchange during Inhalation of $\mathrm{CO}$

\begin{tabular}{|c|c|c|c|c|c|c|c|c|c|}
\hline Goat & $\mathrm{COHb}$ & VE & $\mathrm{f}$ & VT & $\mathrm{PaCO}_{2}$ & $\dot{\mathrm{V}}_{2}$ & $\dot{\mathrm{V}} \mathrm{CO}_{2}$ & RER & $\dot{\mathrm{V}} \mathbf{D} / \dot{\mathrm{V}}_{\mathrm{E}}$ \\
\hline & $\%$ & liters/min & $\min ^{-1}$ & $\mathrm{~cm}^{2}$ & $m m \mathrm{Hg}$ & \multicolumn{2}{|c|}{$\mathrm{cm}^{3} / \min$} & & \\
\hline \multirow[t]{2}{*}{13} & 0 & 5.75 & 17 & 338 & 32 & 218 & 172 & 0.79 & 0.43 \\
\hline & 49 & 12.58 & 38 & 331 & 34 & 238 & 321 & 1.35 & 0.47 \\
\hline \multirow[t]{2}{*}{14} & 0 & 8.14 & 23 & 354 & 34 & 290 & 203 & 0.70 & 0.48 \\
\hline & 54 & 16.47 & 54 & 305 & 34 & 254 & 329 & 1.30 & 0.58 \\
\hline \multirow[t]{2}{*}{15} & 0 & 10.00 & 32 & 312 & 34 & 203 & 180 & 0.89 & 0.62 \\
\hline & 43 & 18.82 & 57 & 330 & 29 & 213 & 320 & 1.50 & 0.58 \\
\hline \multirow[t]{2}{*}{16} & 0 & 5.15 & 20 & 257 & 33 & 185 & 142 & 0.77 & 0.41 \\
\hline & 51 & 8.47 & 36 & 235 & 33 & 181 & 208 & 1.15 & 0.47 \\
\hline
\end{tabular}

$\mathrm{VO}_{2}$, oxygen uptake; $\mathrm{VCO}_{2}, \mathrm{CO}_{2}$ elimination; $\mathrm{RER}$, respiratory exchange ratio; $\mathrm{VD} / \mathrm{VE}$, ventilation of physiologic deadspace expressed as a fraction of minute ventilation. See Table I for other abbreviations. 
different from the carotid bodies with regard to nature of stimulus and time-course of response of these sensors. Such differences have not been previously described.

In considering other possibilities, the independence of the phenomenon from a heightened medullary chemoreceptor response to $\mathrm{CO}_{2}$ was demonstrated by the lack of enhancement of ventilatory responsiveness to carbon dioxide. We also ruled out hemodynamicinduced pulmonary edema by the absence of pulmonary wedge pressure changes in two goats. Systemic acidosis is unlikely since it was only observed in two of the goats studied.

We then considered the possibility of cerebral acidosis. The data clearly show that the delayed hyperpnea caused by carbon monoxide was consistently accompanied by significant decreases in $\mathrm{pH}$ and bicarbonate concentration and increases (although not equimolar) in lactate concentrations of the cisternal CSF fluid. The explanation for the lack of stoichiometric correspondence between the decrease in bicarbonate and increase in lactate concentrations is not apparent. However, similar findings have been observed in a roughly analogous preparation involving hypoxic hypoxia in peripherally chemodenervated rabbits (19). Measurements of bicarbonate and lactate levels in simultaneously drawn arterial blood samples showed that these remained at base-line values in the systemic circulation during most studies, further confirming the relation between cerebral acidosis and hyperventilation. This finding suggests that the brain may be less well "protected" from hypoxia than systemic tissues as a whole. Such a concept deserves further study.

It should be noted that when the central chemoreceptor mechanism of intact unanesthetized goats is stimulated by ventriculocisternal perfusion with acidic fluid the evoked ventilatory response tends to involve an increase in tidal volume more than an increase in respiratory rate although there is a clear increase in rate when the fluid is made more acid by the inhalation of $\mathrm{CO}_{2}(20)$. Since in the present studies inhalation of $\mathrm{CO}$ caused a proportionately greater increase in respiratory rate than in tidal volume, it is possible that stimulation of the central acid-sensitive chemoreceptor was not the only mechanism involved in the observed $\mathrm{CO}$-induced hyperpnea. It is of interest in this regard that Miller and Tenney recently described tachypnea with a decrease in tidal volume when peripherally chemodenervated cats were exposed to hypoxic gas mixtures for as little as $30 \mathrm{~s}$. They believed that the response was too rapid to be due to accumulation of acid and postulated an effect of hypoxia upon the diencephalon (21). It is known that direct stimulation of the diencephalon, or release from an inhibitory influence of higher regions by decortication, may cause tachypnea (22). Thus, the increase of tidal volume with proportionately greater increase in respiratory rate caused by inhalation of $\mathrm{CO}$ in the present studies could have represented both stimulation of the acid-sensitive central nervous chemoreceptor and an effect of hypoxia on higher centers. The latter effect cannot be specified at present but could have involved either inhibition of cortical activity or activation at the diencephalic level.

Finally, the phenomenon of "cardiodynamic hyperpnea," described by Wasserman and co-workers (14), must be considered as a possible contributing factor to $\mathrm{CO}$-induced hyperpnea. These workers noted isocapnic hyperpnea in anesthetized dogs upon infusion of isoproterenol. The phenomenon, which was present after removal of the carotid bodies, was closely tied to the increase in cardiac output and thus seemed likely to be related to the consequent mobilization of blood and tissue $\mathrm{CO}_{2}$ stores. The receptors responsible for matching ventilation to the increased $\mathrm{CO}_{2}$ delivery to the lungs were not identified. That a similar phenomenon was operative during inhalation of $\mathrm{CO}$ is suggested by the following considerations:

(a) The substantial increases in heart rate and pulse pressure suggest that there was an increase in cardiac output during inhalation of $\mathrm{CO}$. In addition, Ayres and co-workers (3) have shown increases in cardiac output with $\mathrm{COHb}$ levels as low as $9 \%$ in unanesthetized subjects.

(b) At a point $(\mathrm{COHb}=20-30 \%)$ when hemodynamic changes were present but ventilation was unchanged arterial $\mathrm{PCO}_{2}$ increased (Fig. 2). This suggests that at this time $\mathrm{CO}_{2}$ delivery to the lungs was augmented but that some form of depression of ventilatory drive may have diminished the expected ventilatory response to this transient hypercapnia. This contention is supported by the observation that depression of ventilation at $\mathrm{COHb}$ levels of $20-30 \%$ was noted when the circulatory response to $\mathrm{CO}$ was diminished by betaadrenergic blockade.

(c) Direct measurements (Table IV) confirmed the elimination of $\mathrm{CO}_{2}$ from tissue stores during the hyperventilation phase.

Thus, it seems likely that both the direct central nervous effect of hypoxia and circulatory changes played a role in determining the pattern of ventilatory response to $\mathrm{CO}$. However, the persistence of hyperpnea (although somewhat reduced) after beta-adrenergic blockade suggests that this phenomenon may be mostly ascribed to the direct central nervous effects.

Ventilatory effects of central nervous system hypoxia. Finally, these studies serve to underscore the complex nature of the non-hypoxia-specific chemoreceptor-mediated ventilatory effects of hypoxia. At least three distinct phenomena seem to be involved. First, there is a 
depressant effect of relatively mild hypoxia. This is illustrated by the initial depression of ventilation that was observed by Davenport and co-workers (23) in chemodenervated dogs which were given $14 \% \quad \mathrm{O}_{2}$ to breathe, by the early hypercapnia (i.e., lack of ventilatory response to the augmented $\mathrm{CO}_{2}$ delivery to the lungs) during inhalation of $1 \% \mathrm{CO}$ by the untreated animals of the present study, and by the depression of ventilation at $\mathrm{COHb}$ levels of $20-30 \%$ in the animals treated with a beta-adrenergic blocking agent. The precise mechanism of this phenomenon is unclear but, since it is triggered by relatively mild hypoxia, it may involve higher brain centers, as suggested by Tenney and co-workers (24) and by Korner and co-workers (25). Second, there is a stimulation of ventilation with more severe or more prolonged hypoxia. This was observed in the same dogs by Davenport and co-workers (23) after $6 \mathrm{~min}$ of inhalation of $14 \% \mathrm{O}_{2}$ and in the present studies when $\mathrm{COHb}$ levels reached $50-60 \%$. Our data suggest that this phenomenon is likely to be due to brain-CSF acidosis but may involve other effects of hypoxia within the brain as well. Last, severe hypoxia ( $\mathrm{COHb}$ of $70 \%$ in our studies) causes respiratory depression, probably due to metabolic insufficiency of respiratory neurons in general. This is not equivalent to death of these neurons, since in all of our studies the apnea which was caused by high levels of $\mathrm{COHb}$ could be reversed by mechanical ventilation with oxygen.

These findings are consistent with previous observations on the nonperipheral chemoreceptor-mediated ventilatory effects of hypoxia in man. Wade and coworkers (26) studied a group of patients after carotid chemoreceptor denervation consequent to bilateral carotid endarterectomy. They found that ventilation, when related to $\mathrm{PcO}_{2}$ level in arterial blood, was less during hypoxia combined with hypercapnia than during hyperoxia combined with hypercapnia. This relative depression of ventilatory drive by hypoxia in functionally chemodenervated subjects is analogous to the lack of ventilatory response to elevation of $\mathrm{PCO}_{2}$ in arterial blood during the early phase $(\mathrm{COHb}=20-30 \%)$ of extended inhalation of carbon monoxide in the present studies. Lugliani and co-workers (27), on the other hand, found no changes in ventilation or in $\mathrm{PCO}_{2}$ of arterial blood during inhalation of $12 \% \mathrm{O}_{2}$ in $\mathrm{N}_{2}$ by a group of subjects who had undergone bilateral excision of their carotid bodies. However, their measurements were made at a single point in time, $8 \mathrm{~min}$ after the onset of hypoxia. Thus, it is possible that the depression of ventilation associated with mild hypoxia, which seems to be an evanescent phenomenon, was missed in these studies. Stimulation of ventilation by more severe central nervous system hypoxia would not be expected to have been observed in either study. In the present studies stimulation of ventilation occurred at $\mathrm{COHb}$ levels of approximately $50 \%$. In order to reduce $\mathrm{O}_{2}$ content in arterial blood by an equivalent amount by hypoxic hypoxia, a $\mathrm{Po}_{2}$ value in arterial blood of under $30 \mathrm{~mm} \mathrm{Hg}$ would be required. In the studies of Wade and Lugliani and their co-workers $\mathrm{Po}_{2}$ values in arterial blood were always above $40 \mathrm{~mm} \mathrm{Hg}$.

The clinical implications of these data go beyond the occasional case of carbon monoxide poisoning. It is generally recognized that the responses of severely hypoxemic patients to $\mathrm{O}_{2}$ administration are quite variable. The responses are frequently very different from those which would be predicted from the responses of normal individuals to acute hypoxia which seem to follow the known stimulus-response characteristics of the peripheral chemoreceptors. For example, it is not uncommon to observe no change in alveolar ventilation when arterial $\mathrm{Po}_{2}$ is raised from 30 to $50 \mathrm{~mm} \mathrm{Hg}$ in a patient with chronic obstructive lung disease although this is the range of greatest effect of $\mathrm{Po}_{2}$ upon ventilation in normal individuals. It seems likely that in such patients concomitant relief of the ventilatory depressant effect of central nervous system hypoxia may offset the decrease of stimulation by the peripheral chemoreceptors. We are unaware of any unequivocal description of the stimulation of ventilation by central nervous hypoxia in a clinical setting. However, as shown by the present data, this may be due to the inherent instability of this state since the hypoxia required to produce the phenomenon appears to be only somewhat less severe than that which produces profound ventilatory depression due to cerebral metabolic insufficiency. In animals this phenomenon has been invoked to explain the ventilatory acclimatization to hypoxia which takes place in the absence of peripheral chemoreceptors (19).

\section{ACKNOWLEDGMENTS}

This study was supported by a research grant from the National Heart and Lung Institute (HL 16022).

The expert technical assistance of Vincent Scoles III and secretarial assistance of Vincetta Niesz are gratefully acknowledged.

\section{REFERENCES}

1. Haldane, J. B. S. 1895. The action of carbonic oxide on man. J. Physiol. (Lond.). 18: 430-462.

2. Haggard, H. W., and Y. Henderson. 1921. Hematorespiratory functions. XII. Respiration and blood alkali during carbon monoxide asphyxia. J. Biol. Chem. 47: 421-432.

3. Ayres, S. M., S. Giannelli, and H. Mueller. 1970. Myocardial and systemic responses to carboxyhemoglobin. Ann. N. Y. Acad. Sci. 177: 268-293.

4. Chiodi, H., D. B. Dill, F. Consolazio, and S. M. Ho:vath. 1941. Respiratory and circulatory responses to 
acute carbon monoxide poisoning. Am. J. Physiol. 134: 683-693.

5. Duke, H. N., J. H. Green, and E. Neil. 1952. Carotid chemoceptor impulse activity during inhalation of carbon monoxide mixtures. J. Physiol. (Lond.). 118: 520-527.

6. Paintal, A. S. 1967. Mechanism of stimulation of aortic chemoreceptors by natural stimuli and chemical substances. J. Physiol. (Lond.). 189: 63-84.

7. Mills, E., and M. W. Edwards, Jr. 1968. Stimulation of aortic and carotid chemoreceptors during carbon monoxide inhalation. J. Appl. Physiol. 25 : 494-502.

8. Santiago, T. V., N. H. Edelman, and A. P. Fishman. 1975. The effect of anemia on the ventilatory response to transient and steady-state hypoxia. J. Clin. Invest. 55: $410-418$.

9. Black, A. M. S., D. I. McCloskey, and R. W. Torrance. 1971. The responses of carotid body chemoreceptors in the cat to sudden changes of hypercapnic and hypoxic stimuli. Respir. Physiol. 13: 36-49.

10. Gemmill, C. L., and D. L. Reeves. 1933. The effect of anoxemia in normal dogs before and after denervation of the carotid sinuses. Am. J. Physiol. 105: 487-495.

11. Edelman, N. H., N. S. Cherniack, S. Lahiri, and A. P. Fishman. 1969. Response of goats to acute, chronic and life-long hypoxia. Fed. Proc. 28: 1223-1228.

12. Tenney, S. M., and J. G. Brooks, III. 1966. Carotid bodies, stimulus interaction, and ventilatory control in unanesthetized goats. Respir. Physiol. 1: 211-224.

13. Marback, E. P., and M. H. Weil. 1967. Rapid enzymatic measurement of blood lactate and pyruvate. Use and significance of metaphosphoric acid as a common precipitant. Clin. Chem. 13: 314-325.

14. Wasserman, K., B. J. Whipp, and J. Castagna. 1974. Cardiodynamic hyperpnea: hyperpnea secondary to cardiac output increase. J. Appl. Physiol. 36: 457-464.

15. Comroe, J. H., Jr., and C. F. Schmidt. 1938. The part played by reflexes from the carotid body in the chemical regulation of respiration in the dog. Am. J. Physiol. $121: 75-97$.

16. Lloyd, B. B., D. J. C. Cunningham, and R. C. Goode. 1968. Depression of hypoxic hyperventilation in man by sudden inspiration of carbon monoxide. In Wates Foun- dation Symposium on Arterial Chemoreceptors. Blackwell Scientific Publications, Oxford. 145-148.

17. Richards, D. W., Jr., and M. L. Strauss. 1928. Circulatory adjustment in anemia. J. Clin. Invest. 5: 161-180.

18. Chiodi, H., J. C. Fasciolo, J. R. E. Suárez, and A. C. Taquini. 1948. Sensitivity of the respiratory center to anemic hypoxia. J. Appl. Physiol. 1: 148-156.

19. S $\phi$ rensen, S. C. 1970 . Ventilatory acclimatization to hypoxia in rabbits after denervation of peripheral chemoreceptors. J. Appl. Physiol. 28: 836-839.

20. Pappenheimer, J. R., V. Fencl, S. R. Heisy, and D. Held. 1965. Role of cerebral fluids in the control of respiration as studied in unanesthetized goats. $A m$. J. Physiol. 208: 436-450.

21. Miller, M. J., and S. M. Tenney. 1975. Hypoxia-induced tachypnea in carotid-deafferented cats. Respir. Physiol. 23: 31-39.

22. Cohen, M. I. 1964. Respiratory periodicity in the paralyzed, vagotomized cat: hypocapnic polypnea. Am. J. Physiol. 206: 845-854.

23. Davenport, H. W., G. Brewer, A. H. Chambers, and S. Goldschmidt. 1947. The respiratory responses to anoxemia of unanesthetized dogs with chronically denervated aortic and carotid chemoreceptors and their causes. $\mathrm{Am}$. J. Physiol. 148: 406-416.

24. Tenney, S. M., P. Scotto, L. C. Ou, D. Bartlett, Jr., and J. E. Remmers. 1971. Suprapontine influences on hypoxic ventilatory control. High Altitude Physiology: Cardiac and Respiratory Aspects. CIBA Found. Symp. 89-102.

25. Korner, P. I., J. B. Uther, and S. W. White. 1969. Central nervous integration of the circulatory and respiratory responses to arterial hypoxemia in the rabbit. Circ. Res. 24 : 757-776.

26. Wade. J. G., C. P. Larson, Jr., R. F. Hickey, W. K. Ehrenfeld, and J. W. Severinghaus. 1970. Effect of carotid endarterectomy on carotid chemoreceptor and baroreceptor function in man. N. Engl. J. Med. 282: 823829.

27. Lugliani, R., B. J. Whipp, C. Seard, and K. Wasserman. 1971. Effect of bilateral carotid-body resection on ventilatory control at rest and during exercise in man. N. Engl. J. Med. 285: 1105-1111. 